\title{
El secreto de los flamencos, de Federico Andahazi, y el otro Aleph
}

\author{
Jorge R. SAGASTUME \\ Dickinson College, Pensilvania
}

\begin{abstract}
RESUMEN
Este trabajo tiene el fin de discutir los temas principales tratados en la novela El secreto de los flamencos, de Federico Andahazi, partiendo de los textos que han regido su composición. Entre estos textos, el más influyente es "El Aleph", de Jorge Luis Borges, que no sólo se menciona de manera específica en la novela sino que además es el tema, que desarrollado por Andahazi parte del concepto del Aleph borgesiano. El cuento de Borges, sin embargo, está regido por el Aleph del matemático Georg Cantor, quien creara un sistema epistémico transfinito y del que Borges se apropia para cuestionar lo que llamamos realidad y sugerir que nada, más allá del lenguaje, es real. Tanto Borges como Andahazi pueden clasificarse como escritores 'ironistas' que, siendo conscientes de la finitud de los sistemas epistémicos que como humanos utilizamos, desarrollan un tipo de escritura que consiste de la permanente redescripción metafórica, no con la intención de establecerse como vocabulario final sino con el propósito de mantener abierto el diálogo intelectual entre las diferentes disciplinas del conocimiento.
\end{abstract}

Palabras clave: Borges, Andahazi, Aleph, matemáticas, filosofía, epistemología.

\section{El secreto de los Flamencos, by Federico Andahazi, and the Other Aleph}

\begin{abstract}
This essay has the purpose of discussing the main issues addressed in the novel The secret of the Flemish, by Federico Andahazi, departing from the texts that have determined its composition. Among these texts, the most influential has been Jorge Luis Borges's "The Aleph"; not only that the story is mentioned specifically in Andahazi's novel but also the ideas developed in it depart from the Borgesian concept of the Aleph. Borges's Aleph, however, comes from the mathematician Georg Cantor, who developed a transfinite epistemological system that Borges makes his own to question what we call reality to later suggest that nothing apart from language is real. Both, Borges and Andahazi, may be classified as 'ironist' writers who, being aware of the finitude of the epistemic systems that we humans utilize, develop a style of writing that is characterized by a constant metaphorical re-description, not with the intention of establishing a final vocabulary but to maintain open the intellectual dialogue among the different disciplines that deal with theories of knowledge.
\end{abstract}

Keywords: Borges, Andahazi, Aleph, mathematics, philosophy, epistemology. 
Rafael Gutiérrez Girardot resume la obra de Jorge Luis Borges como la tarea de un individuo que inicia su carrera literaria como escéptico para acabar como ironista; creo que lo mismo se puede decir de Federico Andahazi (82). ${ }^{1}$ En una entrevista a Andahazi, Pedro B. Rey indaga sobre los orígenes de las complejas ideas tratadas en la novela El secreto de los flamencos; el autor, un poco evasivamente, responde que:

toda novela está escrita en algún lugar antes de escribir la primera palabra. Está en el orden de aquello que Platón llamaba la rememoración. Me da cierta tranquilidad al sentarme a escribir creer que esa novela ya está escrita en alguna parte. Me agradaría decir que, siguiendo ese hilo, uno ya tiene cierta cantidad de novelas escritas, en algún lugar, para el resto de su vida. Esta novela, por ejemplo, la pensé completamente antes de empezarla. ${ }^{2}$

En su respuesta Andahazi da a entender que, precisamente, como Platón lo indicara, todo es rememoración y que a través de ella él ha tejido la trama de su novela. Pero lo que dice Platón en la República, es que todo lo que hacemos, pensamos y decimos en esta vida mortal proviene de una anterior; una vida en otro lugar donde vivíamos con un cierto dios, y los recuerdos de esa otra vida se han permeado y entrado en nuestra realidad, pero ninguna de las ideas que surgen en esta vida son de creación propia sino que proceden de un creador supremo y absoluto.

Dada su complejidad El secreto de los flamencos puede dar lugar a varios trabajos de interés pero una de las cosas que quisiera proponer en este ensayo es que, como el autor lo afirma, la novela ya estaba escrita en algún lugar; esa rememoración a la que Andahazi se refiere, no obstante, no es en realidad de características platónicas sino que se trata de la rememoración de lecturas previas y del resultado de un serio trabajo de investigación que de manera muy borgesiana se convierte en ficción. Estas lecturas previas de Andahazi, es verdad que proceden de Platón; también de Aristóteles y otros, pero el autor llega a ellas y las utiliza en un contexto específico a través de Borges, y en particular por medio del cuento "El Aleph". Sin embargo, la finalidad de este trabajo no es la de descubrir textos ocultos en la novela de Andahazi; mi intención es la de esclarecer las ideas que la obra pretende comunicar a través de los textos que han regido su composición. Y entre estas ideas, las centrales que quisiera discutir aquí son la del cuestionamiento de lo que llamamos realidad y la de la dificultad de su explicación o representación a través de los sistemas con los que

1 Téngase en cuenta que el término ironista, en este ensayo, no funciona como simple adjetivo que describe a una persona irónica, o que utiliza ironía, sino que se refiere a ciertos autores, como más recientemente lo estudia con detenimiento Richard Rorty, que crean una obra con la intención específica de ser una metáfora de la realidad, con el propósito de obligar al lector a considerar el universo desde una perspectiva que se caracteriza por reconocer abiertamente la falta de presunción de establecerse como un vocabulario final, o descripción definitiva, tal como tiende a hacerlo la ciencia, e incluso la filosofía y hasta la crítica literaria (Véase Richard Rorty, Contingency, Irony, and Solidarity).

${ }^{2}$ Fuente electrónica (Véase Pedro B. Rey en la bibliografía). 
contamos, sean éstos lingüísticos, artísticos, o científicos. En otras palabras, lo que plantean las obras que dan forma al texto andahaziano es la imposibilidad de llegar a un vocabulario final, ${ }^{3}$ o a una descripción definitiva de los infinitos elementos que componen el universo. ${ }^{4}$ Pero el texto de Andahazi, como los de su maestro Borges, proponen que aunque no podamos jamás determinar un vocabulario final, sí debemos continuar produciendo descripciones y redescripciones, siempre y cuando seamos conscientes de los juegos lingüísticos a los que nos suscribimos y de la finitud de los mismos. ${ }^{5}$ A fin de desarrollar los temas aquí sugeridos, en primer lugar hará falta establecer la conexión entre la novela andahaziana y el cuento de Borges, para luego demostrar cómo, a partir del cuento borgesiano y de los textos que lo rigen, Andahazi teje la trama de su novela presentando una visión alternativa, o una redescripción, de las ideas propuestas por Borges en "El Aleph", siguiendo así los pasos de su maestro y convirtiéndose como él en un ironista.

Sabemos que en Borges siempre aparecen temas que se repiten de manera casi obsesiva, presentándose cada vez argumentos superpuestos, o redescripciones de los mismos; entre ellos podemos mencionar el infinito y el absoluto. No hay espacio aquí para entrar en una discusión, siquiera superficial, de los textos borgesianos que tratan estos temas y el cómo el autor lo hace, ${ }^{6}$ pero, como ya se ha sugerido, el que está directamente relacionado a este ensayo y que establece el marco teórico de la novela de Andahazi es "El Aleph", en el que ese supuesto orificio en un sótano de la calle Garay despliega el Todo: lo pasado, lo presente y lo por venir, además de dilucidar todos los secretos del universo, resolviendo así toda aporía y explicando toda paradoja. Ese orificio, esa "esfera cuyo centro está en todas partes y la circunferencia

${ }^{3}$ Utilizo la expresión "vocabulario final" siguiendo el modelo de Richard Rorty, quien creó la terminología al referirse a la fútil búsqueda de las distintas disciplinas de hallar una descripción final o definitiva de los distintos elementos que componen nuestra realidad.

${ }^{4}$ Como nota de aclaración, el término "universo" en este trabajo se utiliza a la manera borgesiana y que se ajusta a la definición del diccionario: "conjunto de todas las cosas creadas", que también coincide con la definición de la palabra "cosmos" (Véase el diccionario de la Real Academia Española: http://buscon.rae.es/draeI/SrvltConsulta?TIPO_BUS $=3 \&$ LEMA=universo). Este conjunto de todas las cosas creadas incluye, por supuesto, al ser humano.

${ }^{5}$ Utilizo aquí la expresión "juego lingüístico" a la manera de Lyotard (Véase Jean-François Lyotard. The Postmodern Condition: A Report on Knowledge, trans. Geoff Bennington and Brain Massumi. Minneapolis: University of Minnesota P., 1984).

${ }^{6}$ Sin pensar con mucho esfuerzo, se me ocurren varios escritos de Borges en los que los fundamentos de los argumentos presentados tienen sus orígenes en la matemática y su relación con el infinito: "El disco", "El libro de arena", "La biblioteca de Babel", "La lotería de Babilonia", "Del rigor de la ciencia", "Examen de la obra de Herbert Quain", "Argumentum ornithologicum", "La perpetua carrera de Aquiles y la tortuga", "Avatares de la tortuga", "El idioma analítico de John Wilkins", "La doctrina de los ciclos", "Pascal", "La esfera de Pascal", "Ruinas circulares", "El inmortal", "La muerte y la brújula", y la lista podría continuar, incluyendo el más agudo de todos: "El Aleph". 
en ninguna" (I, 625) y que adquiere la forma de un hexágono en "La biblioteca de Babel", vendría a ser el conjunto absoluto de todos los conjuntos que componen el infinito universo. Partiendo de este planteamiento, Andahazi hila una trama cuasi histórica en la que se retrata la búsqueda y el hallazgo de un Aleph, a través del arte de la pintura, que abriría las puertas al entendimiento de la realidad y, a través de ello, permitiría hallar una manera de explicarla o de representarla a través de la pintura, que consta de la fusión de la forma, dada mediante la perspectiva matemática, y del color absoluto. Pero este Aleph andahaziano no se halla en un sótano de la calle Garay en Buenos Aires sino en otro ubicado en la Calle del Asno Ciego, en Brujas.

Aparte de esta feliz coincidencia que aparece en ambos textos hay otras que establecen la conexión entre la novela de Andahazi y Borges con bastante claridad, y mediante esta afirmación no estoy sugiriendo plagio de parte de Andahazi, puesto que éste ingeniosamente le da a conocer al lector sus fuentes. Por ejemplo, el narrador revela que el "monje Giorgio Luigi di Borgo, que aseguraba haber visto el mítico Aleph" (Andahazi: 193), más de cuatrocientos años después vio lo mismo que el maestro Monterga, en la novela de Andahazi, ve:

vi un laberinto roto (era Londres), vi interminables ojos inmediatos escrutándose en mí como en un espejo, vi todos los espejos del planeta y ninguno me reflejó [...] sentí vértigo y lloré, porque mis ojos habían visto ese objeto secreto y conjetural, cuyo nombre usurpan los hombres, pero que ningún hombre ha mirado: el inconcebible universo. (194)

Esta cita, tomada de El secreto de los flamencos, en realidad es una cita de una cita, puesto que procede, palabra por palabra, del cuento "El Aleph" y que, a mi modo de verlo, se convierte en el nodo central que determina las ideas desarrolladas a lo largo de la novela que aquí estudiamos. ${ }^{7}$

Si bien el Aleph de Andahazi proviene del de Borges, el de Borges parte de otro, y Andahazi hace uso de éste también. Hacia el final del relato borgesiano, el narrador señala que el Aleph es la primera letra del alfabeto hebreo, el En Soph para la Cábala, y el símbolo de los números transfinitos para la Mengenlehre (627). Las tres cosas, sin embargo, están íntimamente relacionadas: el Aleph es la primera letra del alfabeto hebreo que dio lugar a la imagen de la divinidad para los cabalistas a través del "En Soph", que es también el conjunto absoluto que contiene todos los conjuntos que

${ }^{7}$ Sabemos que se ha conservado el manuscrito del cuento "El Aleph" en el que el autor primero utiliza mihrab en lugar de Aleph. Tal como lo indica Ibn Hajar al-Asqalani, en Fath al-Bari, originalmente la palabra mihrab no tenía una connotación religiosa y designaba un lugar especial en una casa; luego pasó a ser un lugar de honor, o trono de los reyes; el profeta Mahoma usa el término para designar su propio cuarto de oración y en el judaísmo continúa utilizándose como "un lugar especial de la casa". En el relato de Borges ese Aleph o mihrab es un lugar, pero no físico (Véase el interesante ensayo de Lisa Block de Behar, 'Borges, the Aleph, and Other Cardinal Points', Review: Latin American Literature and Arts (May 2005; 70 (38 [1]), 7-16). 
componen el universo, y los números transfinitos, cuyo símbolo también es el Aleph, es el sistema epistémico que permitió articular la teoría de los conjuntos (que es la rama de la matemática que estudia la relación entre conjuntos) creada por el matemático Georg Cantor (1845-1918) con el fin de proponer un lenguaje que vaya más allá del lenguaje finito con el que nos regimos y así poder hablar del infinito sin que esta discusión sea rotulada de metafísica. La diferencia entre el Aleph de Cantor y el de Borges, como bien lo señala Floyd Merrell, reside en que el primero creía en la existencia de un absoluto, mientras que el postrero no creía, necesariamente, en tales arquetipos eternos; su interés en ellos no estaba en la posibilidad de que fueran reales, sino en que ellos le permitían plantear que posiblemente nada fuera real, precisamente porque nuestros juicios sobre la realidad que nos rodea están determinados por el conocimiento que recibimos mediante los sistemas lingüísticos que contamos y que se caracterizan por su finitud (61-2). Todo lo que resulta una paradoja es paradoja dentro de los límites finitos de nuestros sistemas epistémicos; toda paradoja deja de ser tal cuando la analizamos más allá de la finitud lingüística que caracteriza nuestros sistemas. La imaginación y la redescripción en la que se mezclan la finitud con la transfinitud es la que nos permite considerar posibles respuestas a las paradójicas preguntas que pueblan nuestro diario vivir sin la pretensión de haber hallado un vocabulario final, y de esto precisamente consta la escritura ironista (Rorty: 29).

De la manera más sucinta posible, y utilizando otro relato borgesiano para hacer la idea más gráfica, explicaremos de qué consta la idea de Cantor para ver cómo la utiliza Borges y luego Andahazi. Sabemos que en "La biblioteca de Babel" se presenta una analogía entre el universo y la biblioteca (Borges, 1989, I: 465) y el cuento en sí trata sobre la infructuosa búsqueda de un catálogo que sea el catálogo de todos los catálogos que reúnen las diversas explicaciones del universo. Pero este catálogo no es una simple lista que contenga todos los títulos habidos y por haber que puedan ser considerados fuentes individuales de conocimiento y que en conjunto puedan explicar definitivamente el universo, sino que se trata de una relación ordenada de títulos que están relacionados entre sí. En otras palabras, se trata de un conjunto absoluto que contenga absolutamente todos los conjuntos de las fuentes de conocimiento y que revele a la vez la relación que existe entre ellos. Pero dentro de este conjunto absoluto tenemos conjuntos y subconjuntos, por ejemplo los conjuntos de libros de literatura, de filosofía, de historia, de ciencias, etc., que a su vez también están compuestos de subconjuntos. Tomemos el conjunto de los libros de literatura: dentro de éste tenemos el subconjunto que comprende todos los libros de poesía, el de los libros de prosa, el de los libros de drama, etc. Así, cada uno de estos subconjuntos son en sí conjuntos individuales, pero determinar el número total y absoluto de elementos y la relación que existe entre ellos, el catálogo (la cardinalidad del conjunto, en términos matemáticos) resulta imposible si partimos de una aritmética finita. Y la aritmética no es sino otro sistema lingüístico que por ser matemático no necesariamente es exacto como suele ser visto. De modo que para poder comenzar a vislumbrar un concepto infinito haría falta primero crear un sistema epistémico que fuera más allá del finito; es así cómo Cantor establece un sistema con este fin, y que hoy en día se lo conoce como el sistema de los números transfinitos (que van más allá 
de los finitos) y que gobierna la matemática actual y ha establecido los fundamentos de la estadística. ${ }^{8}$ Decir números transfinitos es otra manera de decir cardinalidad, es decir el número de elementos que un determinado conjunto contiene. No requiere mucha imaginación cuando hablamos de conjuntos finitos, pero al pensar en conjuntos infinitos este concepto resulta difícil de vislumbrar. Cantor entonces estableció distintos niveles del infinito y a cada uno de ellos le dio una cardinalidad específica mediante la primera letra del alfabeto hebreo, el Aleph, seguida de un número para indicar cada nivel de infinitud (Aleph-cero, Aleph-1, etc.). Esta cardinalidad, por supuesto, no es determinada por puro capricho sino que responde a un sistema aritmético también transfinito y bien fundamentado, pero no entraremos en detalles sobre ello puesto que no vienen al caso aquí. Lo que quiero destacar mediante estas explicaciones sobre el Aleph cantoriano es que Borges parte de éste, que a la vez parte de la Cábala, que parte del En Soph, para hablar del conjunto absoluto que contiene todos los conjuntos y al que Platón, como los cabalistas, llamó dios (Aczel: 36). Borges y Andahazi, sin embargo, no se suscriben necesariamente a estas ideas de la misma manera que lo hace Cantor sino que las utilizan para cuestionar la realidad y sugerir además que toda descripción o representación es arbitraria a través de los sistemas epistémicos y, por consiguiente, ninguna descripción de la realidad es final o definitiva.

El tema de la imposibilidad de expresar el absoluto, si éste fuese asequible, o de explicar incluso cualquier elemento de la realidad, a través del lenguaje o de la pintura, es antiguo y proviene del Libro X de la República de Platón. Es conocido como la batalla entre la filosofía y la poesía (o el arte). Platón propone que en la república ideal la tarea de impartir conocimiento sobre la verdad habrá de recaer en el filósofo y no en el artista (pintor o poeta), puesto que éste, a) recurre a las emociones, lo más bajo del ser, a la hora de describir la realidad; b) por recurrir a la emoción, destruye la razón y, c) el artista, por ser tan sólo un imitador de la apariencia de la

${ }^{8}$ Un libro que Borges consultaba con frecuencia y del que estas ideas parten es Matemáticas e imaginación, de E. Kasner y J. Newman. Este tema ha sido estudiado por Juan Antonio Hernández (Véase "Biografía del infinito: La noción de transfinitud en Georg Cantor y su presencia en la prosa de Jorge Luis Borges").

9 Borges, en su ensayo titulado "El idioma analítico de John Wilkins" nos informa que "[h]a registrado las arbitrariedades de Wilkins, del desconocido (o apócrifo) enciclopedista chino y del Instituto Bibliográfico de Bruselas; notoriamente no hay clasificación del universo que no sea arbitraria y conjetural. La razón es muy simple: no sabemos qué cosa es el universo. 'El mundo - escribe David Hume- es tal vez el bosquejo rudimentario de algún dios infantil, que lo abandonó a medio hacer, avergonzado de su ejecución deficiente; es obra de un dios subalterno, de quien los dioses superiores se burlan; es la confusa producción de una divinidad decrépita y jubilada, que ya se ha muerto' (Dialogues Concerning Natural Religion, V. 1779). Cabe ir más lejos; cabe sospechar que no hay universo en el sentido orgánico, unificador, que tiene esa ambiciosa palabra. Si lo hay, falta conjeturar su propósito; falta conjeturar las palabras, las definiciones, las etimologías, las sinonimias, del secreto diccionario de Dios" (II, 86). 
realidad, nos aleja de la habilidad de comprenderla tal como es (Platón: 830). Pero según Platón, a través de la rememoración y del uso de la razón, podemos tener acceso a la verdad y también comunicarla por medio de un lenguaje no metafórico; es decir que para Platón se puede llegar a un vocabulario final mediante la razón. ${ }^{10}$ Recordemos, como se mencionó antes, que Platón era partidario de la existencia de un ser supremo y creador de todo; de un absoluto que fuese el conjunto de todos los conjuntos, y al que llamó dios y también "idea", es decir la idea original, creadora de todo.

Tomando como punto de partida esta batalla proveniente de la República, y a la cual se alude con frecuencia a lo largo de la obra de Borges, Andahazi escoge un marco histórico que nos pone aún frente a otra batalla: la que existió durante el renacimiento entre las escuelas de pintura florentina y flamenca. La primera, según la novela, en busca de un absoluto logra el desarrollo máximo posible de la perspectiva matemática (que básicamente consiste en hacer visible la dimensión, tal como aparentemente la percibe el ojo humano) para representar las formas del universo (73), ${ }^{11}$ mientras que la flamenca se caracteriza por la facultad de producir los mejores colores, los más brillantes y los de secado más rápido de la época (99). La fusión de forma (dimensión) y color dan lugar a la representación de lo visible o también denominado sensible. Pero esa unión no es suficiente, puesto que aun cuando el dominio del arte de la pintura se desarrollara al máximo, siguiendo los estatutos platónicos, todavía continuaría siendo una imitación de la apariencia de la realidad, pero no la realidad en sí. Consideremos, por ejemplo, el siguiente diálogo procedente del Libro X en el que se discute la representación de la realidad:

You could do it most quickly if you choose to take a mirror and carry it about everywhere. You will speedily produce the sun and all the things in the sky, and speedily the earth and yourself and the other animals and implements and plants and all the objects of which we just now spoke. Yes, he said, the appearance of them, but not the reality and the truth. Excellent, said I, and you come to the aid of the argument opportunely. For I take it that the painter too belongs to this class of producers, does he not? Of course. (Plato: 821)

Hoy en día esta es una observación obvia, pero en el tiempo histórico que enmarca la novela de Andahazi existía el convencimiento de que esta fusión perfecta y

${ }^{10}$ Silvia G. Kurlat Ares sugiere que Borges considera estas ideas partiendo de Kant, pero en realidad las propuestas kantianas tienen su origen en Platón (Kurlat Ares: 6).

${ }^{11}$ En realidad, existe cierta discrepancia entre si fueron los florentinos o los valencianos los que alcanzaron el mayor dominio de la perspectiva; se dice que hacia fines de los años 1400 y durante los 1500, la perspectiva fue el área de los últimos, y el más prominente fue Giorgione. Entre otras cosas, los artistas trataron asiduamente de usar el punto en el infinito en sus obras, un punto que se desvanece en el centro del cuadro, y hacia él pintaban la escena; con esto comunicaban la idea de la infinitud del universo y a la vez la inhabilidad de representarlo todo (Aczel: 41-44). 
absoluta podía lograrse y así restaurarse la posición del artista, que había quedado en menos a partir de los argumentos platónicos. ${ }^{12}$

Teniendo en cuenta la idea de que existía un ser supremo y absoluto, era lógico para los pintores de la época pensar que detrás de la realidad visible que el ojo humano percibe debía de existir una esencia, ${ }^{13}$ y para poder representar la realidad tal como es, entonces, primero haría falta aprehender esa esencia, o lo que Andahazi, partiendo de Borges, denomina el Aleph, y que en la novela el maestro Monterga, refiriéndose sólo al conjunto absoluto de los colores que contiene todos los colores del universo, llama el color en su estado puro:

[s]i la realidad sensible era una mísera copia del mundo de las ideas, entonces la pintura, como representación artificiosa de la naturaleza, era apenas una copia de la copia. De modo que si existiera el color en estado puro, quizá la pintura dejaría de ser una deficiente reproducción y alcanzaría a convertirse en un arte verdaderamente sublime. (162-63)

La posibilidad de alcanzar este absoluto es lo que lleva a Monterga a someterse al meticuloso estudio de los textos de Aristóteles, quien concluye que la "esencia del color está en la propiedad de los cuerpos de mover al diáfano en acto" (Andahazi: 163). Y diáfano era el vocablo que empleaba Aristóteles para referirse al transparente éter lumínico, la luz, que para él era de inexplicable procedencia divina (Aristóteles, 1028b: 8). Ahora bien, siguiendo la línea aristotélica, Monterga decide que el color era "la frontera entre Dios y el mundo sensible" (Andahazi: 164). Pero si el color es la frontera entre dios y la realidad sensible, y si el color es determinado por el diáfano al que Aristóteles se refirió, asir el color sería alcanzar el diáfano, o "el color en estado puro", y que sería esencial a fin de preparar todos los demás colores que el ojo percibe, tal como lo propone la novela. En otras palabras, y para volver sobre los pasos de Borges y Cantor, ese color en estado puro equivaldría a un cierto Aleph, en cual todos los demás colores de la realidad (subconjuntos) estarían incluidos.

Esta obsesión con la posibilidad de catalogar los diversos elementos del universo de forma definitiva se presenta en la novela de Andahazi mediante diferentes métodos. Aparte de Monterga, otro de los personajes de la novela, Juan Díaz de Zorrilla, o Il Castigliano, pensaba que "si el Universo sensible está compuesto de materia y a cada sustancia le es dado un color, las leyes de la pintura no deberían ser diferentes de las leyes de la naturaleza" (115). Il Castigliano propone así que con la

${ }^{12}$ El estudio de este tema en la novela de Andahazi, a mi modo de leer el texto, tiene el propósito de redescribir estas antiguas ideas para cuestionar nuestra percepción de la realidad y la arrogancia de ciertas disciplinas que se creen en posesión de un vocabulario final sobre ciertos aspectos de la realidad.

${ }^{13}$ Sobre el tema, Bertrand Russell observa que: "what the senses immediately tell us is not the truth about certain sense-data which, so far as we can see, depend upon the relations between us and the object. Thus what we directly see and feel is merely 'appearance', which we believe to be a sign of some "reality' behind" (Russell: 16). 
perspectiva matemática de los florentinos para representar las formas no basta, como tampoco es suficiente el maravilloso color logrado por los flamencos; a ello hace falta "insuflarle el espíritu, imperceptible a la vista", o una cierta esencia, y basándose en este principio "había elaborado una cuidadosa clasificación de ideas a las cuales les correspondían determinados elementos que transportaban, en su sustancia, los espíritus que animan la materia" (116) y así, "los pigmentos que utilizaba [de Zorrilla] surgían de una particular concepción del Universo, vista a través de la pintura. Sostenía que, para que la pintura no fuese más que un torpe y defectuoso simulacro, el color debía ser inmanente al objeto representado" (116). Siguiendo esta lógica preparaba entonces sus colores con elementos de la realidad sensible; hasta con sangre humana si era ésta la que quería representar.

Podemos notar que Andahazi, como Borges, juega con la idea de los vocabularios finales a través de las diferentes disciplinas para sugerir que la representación de cualquier elemento del universo depende de un sistema específico que es finito y, por consiguiente, incapaz de una explicación definitiva. En el caso de El secreto de los flamencos, los personajes tratan de ir más allá del sistema tradicional (o finito) del arte con el fin de invalidar las sentencias platónicas. Pero, como dijimos, para lograr esto haría falta tener acceso al color en estado puro. Ahora bien, una vez hallado ese color puro, la esencia, ese mítico Aleph, el problema de la representación no queda resuelto, puesto que habría que hallar una manera de fijar esa esencia al lienzo. El narrador del cuento borgesiano, después de haber visto $s u$ Aleph, se halla frente a una situación semejante puesto que la descripción o representación de lo que vio resulta imposible a través del sistema lingüístico que ha heredado de sus antepasados:

En ese instante gigantesco, he visto millones de actos deleitables o atroces; ninguno me asombró como el hecho de que todos ocuparan el mismo punto, sin superposición y sin transparencia. Lo que vieron mis ojos fue simultáneo; lo que transcribiré, sucesivo, porque el lenguaje lo es. (Borges, 1989, I: 625)

Lo que el narrador ve es simultáneo (es decir, sincrónico), mientras que el lenguaje finito con el que cuenta para describir es sucesivo (es decir, diacrónico), de manera que aunque fuésemos capaces de descubrir ${ }^{14}$ una verdad absoluta no nos pone en ventaja respecto a otros individuos puesto que su explicación o representación definitiva resultaría imposible. De esta manera Borges no sólo cuestiona la validez de las distintas disciplinas del conocimiento proponiendo indirectamente que ningún sistema epistémico permite la explicación de un fenómeno, sino que también pone en tela de juicio nuestra percepción de la realidad que nos rodea puesto que inevitablemente está teñida por los diferentes sistemas lingüísticos que utilizamos y por medio de los cuales emitimos ciertos juicios sobre lo que vemos.

${ }^{14}$ Utilizo el verbo descubrir en cursiva para enfatizar la característica del vocablo puesto que, siguiendo la idea de los Románticos alemanes, la verdad no se descubre sino que se crea a través del lenguaje (Rorty: 3 ). 
Andahazi, por otro lado, intenta desarrollar aún más el tema borgesiano sugiriendo a través de la novela un método para representar ese Aleph. Ese método consta de una fórmula química que produce un óleo capaz de transferir el Aleph al lienzo. Según la novela, la escuela florentina de la pintura contaba con Cosimo da Verona como máximo representante de la misma, quien además había sido el maestro de Francesco Monterga. Cosimo da Verona no sólo había logrado la supremacía en lo que toca a la perspectiva matemática para representar las dimensiones de los elementos del universo, sino que también había tenido acceso al color en estado puro y a la fórmula química que permitía su transferencia a la tela. Pero tal privilegio tuvo una vida muy breve ya que pierde la vista sin poder disfrutar de tal hallazgo. Después de semejante tragedia, da Verona decide no compartir el secreto con su discípulo, y en lugar de ello le deja en herencia el Diversarum Artium Schedula de Eraclius (Andahazi: 38). ${ }^{15}$ Monterga, habiendo logrado como su maestro el dominio de la perspectiva, con la ayuda de uno de sus discípulos, Pietro della Chiesa, dedica el resto de su vida a la decodificación de este manuscrito a fin de hallar la manera de fusionar dimensión (o forma) y color para que la pintura dejara de ser simplemente un simulacro de la realidad. Para ello no sólo recurre a los postulados de la matemática, la física y la química, sino que hasta hace uso de la cábala, la numerología y la alquimia (161), pero sin alcanzar los resultados deseados.

Del otro lado del campo de batalla, según la novela, los flamencos contaban con Greg van Mander como máximo representante de su escuela de pintura. El rey Felipe III le había encomendado a Greg la tarea de hallar la fórmula de la preparación del color del famoso pintor Jan van Eyck (?-1441). ${ }^{16}$ Greg no sólo había logrado reproducir las técnicas de van Eyck, sino que sus óleos eran incluso superiores, puesto que había logrado tener acceso al color en estado puro y había creado una cierta fórmula química que permitía su fijación a la tela, pero, señala el texto andahaziano, "el propio ejecutor de la maravillosa receta apenas llegó a conocer su invención, el Óleo Precioso, ya que, como Cosimo da Verona, perdió la vista durante su preparación. Desde aquél entonces Greg había jurado no volver a elaborar el preciado óleo" (184), y le había prohibido a su hermano menor, Dirk, que fuese al sótano de su casa, ubicada en la Calle del Asno Ciego, donde se hallaba el secreto de la preparación de dicho óleo.

A diferencia de Borges, lo que Andahazi propone en su novela es que hallar un método definitivo de representación de la realidad equivale a ser un dios. Borges nunca hace tales aseveraciones. Por medio de la novela de Andahazi sabemos que

${ }^{15}$ Es obvio que Andahazi consulta esta obra, muy probablemente a través de $A$ Critical Essay on Oil Painting; Proving that the Art of Painting in Oil Was Known Before the Pretended Discovery, by John (Jan) y Hubert van Eyck, donde también se editan los manuscritos de Theophilus (De Arte Pingendi) y el del Eraclius (De Artibus Romanorum).

${ }^{16}$ Greg van Mander es un personaje de ficción en la novela, por supuesto, pero van Eyck no lo es. Se desconoce la fecha de nacimiento de van Eyck, pero sí se sabe que murió en Brujas en 1441, después de haber servido como pintor de cámara. 
para que el color en estado puro pudiese ser transferido al lienzo haría falta un método, un sistema transfinito y, como dijimos, Greg es el creador de tal sistema. El producto resultante de la fórmula creada por Greg es un líquido brillante y transparente que al ser añadido al color lo transforma en el verdadero color de la realidad, y que al ser fusionado con la forma dada a través de la perspectiva, permite la representación de la realidad que el artista escoge representar. Repasemos el pasaje de la novela que trata sobre el proceso de fijación del color en estado puro al lienzo:

En el principio fue el Oleum Pretiosum ${ }^{17}$, y luego Greg hizo las tinieblas que se abrían en el haz del abismo, y lo llamó Negro. El espíritu de Greg se movía sobre el haz del abismo. Y dijo Greg: sea el Azul: y fue el Azul. Y, sin verlo, supo que el Azul era bueno. Y apartó Greg la luz de las tinieblas. Y dijo Greg: hágase el Amarillo. Y fue el Amarillo. Y así creó, también, el Rojo. Y el Rojo era bueno. Greg, otra vez dueño y señor de su universo, hacía y deshacía según su voluntad y, ciego como era, envuelto en sus íntimas tinieblas, creaba colores que ni siquiera podía ver. (192)

Dos cosas importantes podemos deducir: en primer lugar, la cita nos remonta a un génesis bíblico y, por ende, a una teoría de un origen; luego, a fin de poder el pintor representar el color de la realidad, tiene que depender de una fórmula externa al color en estado puro o Aleph. Esto sugiere que en todo sistema humano, y por consiguiente finito, hace falta siempre recurrir a otro sistema, que a la vez depende de otro, y así ad infinitum. Por otro lado, el pasaje también sugiere un sistema finito aún dentro de lo que nosotros consideraríamos infinito. Es decir, si existe un dios supremo y absoluto al estilo de Platón, es posible que también éste se halle limitado por el sistema que lo rige y que exige otro externo, o transfinito, que le permita llevar a cabo la creación; ese otro sistema, a la vez, requiere otro superior, y así sucesivamente hacia un infinito.

En la obra de Borges, aunque uno puede llegar a conclusiones semejantes, el lector nunca se encuentra con propuestas de este tipo; quizá porque para Borges estos arquetipos eternos no vienen al caso, o son innecesarios para comunicar los mensajes o ideas que el autor desea impartir. Aún así, Borges y Andahazi, por medios diferentes cuestionan la existencia de un conjunto absoluto que contenga todos los conjuntos, un origen, y por ende la posibilidad de un vocabulario final que pueda definitivamente explicar la realidad. Pero más que cuestionar la existencia de este conjunto absoluto, lo que en realidad ambas obras cuestionan es la posibilidad de representar este conjunto, o siquiera un simple y aislado elemento de la realidad.

Esta falibilidad de representación, en el caso de Borges, como ya se ha sugerido, tiene sus raíces en la finitud de los sistemas epistémicos con los que contamos, incluso el del lenguaje matemático; ningún sistema, según Borges, es capaz de representar de manera sincrónica algún elemento de la realidad puesto que todo

${ }^{17}$ Andahazi utiliza de manera indistinta Óleo Precioso y Oleum Pretiosum; a lo largo del ensayo, para evitar confusiones, utilizaremos el primero. 
sistema se caracteriza por ser diacrónico. La única posibilidad de expresar un cierto elemento de la realidad de manera total está en hallar un lenguaje en el que exista absoluta correspondencia entre el significado y significante. Probar, o siquiera proponer, la posibilidad de la existencia de tal lenguaje no es lo que le interesa a Borges puesto que, como Richard Rorty lo sugiriera mucho después que el autor argentino, sabe que "[t]he suggestion that truth, as well as the world, is out there is a legacy of an age in which the world was seen as the creation of a being who had a language of his own" (5). Pensar en la creación de un lenguaje ideal, o de hallar uno, equivaldría a divinizar la realidad, a atribuirle un creador inalcanzable al estilo de Platón. La divinización, entonces, de cierta manera produce la cesación de todo diálogo, puesto que asume que no hay forma de saber ciertas cosas y por lo tanto no tiene sentido discutirlas. Pero Borges es consciente de que los sistemas lingüísticos no pueden ser un medio entre el ser y la realidad, ni siquiera el matemático, científico o filosófico y precisamente esto es lo que le permite a él y a todo ser humano la teorización de ideas de manera constante sin el interés de hallar un vocabulario final puesto que todo sistema epistémico es metafórico. Ya en 1921 Borges declaraba que "[n]o existe una esencial desemejanza entre la metáfora y lo que los profesionales de la ciencia nombran la explicación de un fenómeno. Ambas son una vinculación tramada entre dos cosas distintas, a una de las cuales se la trasiega en la otra. Ambas son igualmente verdaderas o falsas" (Borges, 1997: 114). De esta manera el lenguaje se convierte en algo que no depende de la realidad y no es un medio entre el individuo y el universo que lo rodea sino que es en sí una entidad independiente que se rige por leyes propias (gramaticales, sintácticas, etc.). Mediante el lenguaje, cualquiera sea éste, creamos diversos sistemas metafóricos mediante los cuales podemos aseverar que algo es verdadero o falso, dependiendo del juego lingüístico al que nos suscribimos. Por otro lado, ni Borges ni Andahazi divinizan la metáfora al estilo de Nietzsche, puesto que ello equivaldría a proponer lo opuesto de los estatutos platónicos. ${ }^{18}$

Ahora bien, siguiendo este razonamiento, podemos concluir que el arte de la pintura también es un sistema de representación independiente y no un medio entre el ser y la realidad. Como ya se sugirió, en la novela de Andahazi el lector se convierte en testigo de una batalla cuasi histórica en la que dos escuelas se enfrentan con el fin de hallar y representar fehacientemente la verdad. La dínamo que motiva esta batalla es la de establecer un vocabulario final a través del arte de la pintura y así invalidar las sentencias platónicas. No obstante, ambas escuelas también saben después de Platón que la realidad sensible tal como la percibimos consta de dos elementos esenciales, forma y color. Pero la forma está dada a través de la perspectiva matemática, y sabemos que la matemática también es un sistema epistémico que por ser matemático no deja de ser metáfora. Tal aseveración siempre ha resultado para los matemáticos difícil de digerir, aunque para los matemáticos analíticos como Morris

${ }^{18}$ Me refiero aquí a la divinización del poeta que Nietzsche propone en su obra Die Geburt der Tragödie aus dem Geiste der Musik. 
Kline la matemática no difiere de cualquier otra disciplina: "[m]athematics is a human activity and is subject to all foibles and frailties of humans. Any formal, logical account is a pseudo-mathematics, a fiction, even a legend, despite the element of reason" (73). Todo sistema representativo es entonces una metáfora de una cierta realidad Si podemos aceptar estas premisas debemos aceptar que la pintura, como el lenguaje, es metáfora de una cierta realidad, y por ser metáfora ya de por sí deja de ser un "mero simulacro de la realidad sensible" (Andahazi: 116) y se convierte en una entidad independiente cuyo propósito no es el de explicar la realidad sino el de proveer renovadas redescripciones de la misma, sin la intención de establecerse como un vocabulario final. Donald Davidson, refiriéndose a la metáfora, también demuestra que todo sistema es metafórico y que si somos capaces de ver el lenguaje bajo esta óptica podemos darnos cuenta que una metáfora encierra en sí todas las explicaciones que de ella puedan establecerse, mientras que ninguna explicación individual es capaz de explicar una simple metáfora; por otro lado, toda explicación, por ser metáfora en sí, está sujeta a múltiples interpretaciones, y éstas a otras, y así hacia un infinito (Davidson: 247). Tanto Borges como Andahzai son conscientes de estas propiedades de los diferentes sistemas de representación, y a través de sus narrativas desdivinizan la realidad y valiéndose de la permanente redescripción mantienen abierto el diálogo entre las distintas disciplinas del conocimiento.

A través de El secreto de los flamencos, como se sugiriera antes, Andahazi también nos lleva reflexionar en cuanto a nuestros juicios sobre la realidad que nos rodea dependiendo del juego lingüístico que adoptamos. Dijimos que el maestro de Monterga le deja en herencia a su discípulo el antiguo escrito de Eraclius titulado Diversarum Artium Schedula. Al final del mismo Monterga descubre un anexo, o libro aparte, que lleva por título Coloribus et Artibus y en la página siguiente aparece un subtítulo: Secretus coloris in status purus, "[p]ero cuando el lector se aprestaba a saciar su curiosidad y daba vuelta la hoja, se encontraba con el fragmento de Los Libros del Orden de San Agustín, entre cuyas letras se intercalaban una sucesión de números dispuestos sin arreglo a algún orden inteligible" (159). Monterga, como todo artista florentino, estaba muy bien versado en la matemática; partiendo de este juego lingüístico, y con la ayuda de su discípulo Pietro, dedica años de su vida tratando de descifrar las progresiones matemáticas de la página en busca de una clave que le aclarara el secreto tan anhelado del mítico Aleph, pero "[c]ada vez que creyó aproximarse a una interpretación de su significado, el laborioso edificio de sentido que había logrado construir terminaba haciendo agua en la siguiente serie numérica" (161). Monterga, juzgando el manuscrito a través del juego lingüístico de la matemática, no se da cuenta que la parte numérica no tiene nada que ver con la matemática en sí. Otro de los discípulos de Monterga, Hubert, es el que descifra la clave, pero lo hace a través de una ilusión óptica. Puesto que Hubert padece de miopía, nota que al ignorar el texto de San Agustín de la página, y dejando tan sólo las cifras numéricas, éstas forman una especie de marcos claramente definidos. Estos marcos tienen exactamente la forma del retablo que el maestro de Monterga, da Verona, había creado y que se titulaba El triunfo de la luz. Cada uno de los grabados del retablo, a la vez, en forma de vía crucis, indican el lugar donde se halla el Aleph y 
la fórmula para fijarlo al lienzo; es así como Monterga descubre que el preciado secreto se encuentra nada más ni nada menos que en el sótano de la casa de su más acérrimo enemigo, Greg van Mander, en Brujas. Monterga había observado y estudiado miles de veces el retablo que su maestro creara y que él mismo conocía por el título El triunfo de la luz, sin embargo todo lo que Monterga veía en él era una delicada obra de arte de naturaleza religiosa. Jamás había siquiera pensado que podría existir una conexión entre el retablo y el Aleph.

De estos temas presentes en las obras de Borges y de Andahazi, además, se desprende otro comentario importante, y es que si fuese posible alcanzar un Aleph, más allá de poder o no explicarlo o representarlo, nuestra vida dejaría de tener sentido. El narrador de "El Aleph", al salir de la casa de Daneri, reflexiona sobre lo acontecido y señala que "[e]n la calle, en las escaleras de Constitución, en el subterráneo, [le] parecieron familiares todas las caras. Tem[ió] que no quedara una sola cosa capaz de sorprender[lo], tem[ió] que no [1]e abandonara jamás la impresión de volver. Felizmente, al cabo de unas noches de insomnio, [1]e trabajó otra vez el olvido" (I, 626). El valor de nuestra existencia, se podría decir, depende en gran medida de la capacidad de sorprendernos ante toda idea que pueda resolver ciertas incertidumbres y que a la vez crea otras nuevas. Después de todo, hallar un absoluto equivale a vislumbrar ese momento en que algo alcanza una máxima profundidad, un máximo sentido, y deja por completo de ser interesante.

Esta idea también está presente en El secreto de los flamencos. Cuando Monterga al fin ve el Aleph en el sótano de la Calle del Asno Ciego, pero no en la forma de un orificio en el espacio como lo ve Borges sino contenido en un cáliz; el narrador señala que en ese momento:

Vio el Todo y la Nada a la vez, vio el blanco y el negro, vio el caos y el cosmos repetirse hasta el infinito y vio el infinito expandido del universo y también el infinito universo, introvertido, aquel que intuyera Zenón de Elea. Fue testigo del principio y del fin, vio la resolución de todas las aporías y comprendió el sentido último de todas las paradojas [...] Y no vio nada más. Nunca más. [...] igual que todos quienes vieron revelado el secreto del color, los ojos de Francesco se apagaron en una noche larga y cerrada. (251-52)

Momentáneamente Monterga ve el Todo y la Nada y la resolución de todas las aporías y el sentido último de todas las paradojas; todo se resuelve, pero el propósito de su existencia llega a un estado terminal puesto que, como su maestro Cosimo da Verona y su enemigo Greg van Mander, él también pierde la vista o, en otras palabras, puesto que lo ha visto todo ya no tiene nada más que ver y lo abraza una completa oscuridad.

Las ideas detrás de ambas obras literarias que aquí estudiamos podrían resumirse mediante una cita tomada de "El Aleph" y que utilizamos al comienzo de este ensayo:

el problema central es irresoluble: la enumeración, siquiera parcial, de un conjunto infinito. En ese instante gigantesco, he visto millones de actos deleitables o atroces; ninguno me asombró como el hecho de que todos ocuparan el mismo punto, sin 
superposición y sin transparencia. Lo que vieron mis ojos fue simultáneo; lo que transcribiré, sucesivo, porque el lenguaje lo es. Algo, sin embargo, recogeré. (Borges, 1989, I: 625)

Borges utiliza el Aleph cantoriano y teje su Aleph con el fin de desdivinizar el Aleph del cual parte y al mismo tiempo proponer que ni siquiera ese sistema de números transfinitos es capaz de representar o explicar la realidad, puesto que incluso esta aritmética transfinita es sucesiva, o diacrónica, e incapaz de expresar lo simultáneo o sincrónico. Pero Borges ha heredado el Aleph cantoriano y a partir del mismo nos lleva a reflexionar una vez más sobre ciertas paradojas que, de haber sido resueltas, hubiesen cerrado todo diálogo. Ese "[a]lgo, sin embargo, recogeré", creo yo, es precisamente lo que hace de la escritura borgesiana una escritura ironista, que consta de proveer renovadas redescripciones, pero el autor es absolutamente consciente de la finitud del sistema epistémico utilizado y no pretende que éste se establezca como un vocabulario final.

Si recordamos la posdata al relato "El inmortal" de Borges, recordaremos también que toda explicación parte de previas explicaciones: "[c]uando se acerca el fin, escribió Cartaphilus, ya no quedan imágenes del recuero; sólo quedan palabras. Palabras, palabras desplazadas y mutiladas, palabras de otros, fue la pobre limosna que le dejaron las horas y los siglos" (I, 544). La herencia que nos dejan nuestros precursores son sistemas, clasificaciones, teorías, todas propuestas a través de palabras, o sistemas epistémicos que si somos capaces de acogerlos y utilizarlos a fin de proveer renovadas redescripciones, hacemos posible la perpetuación del diálogo entre las disciplinas. Y esto es importante especialmente en estos momentos en los que la presión académica promueve más y más la especialización, cerrando así las puertas al desarrollo intelectual que sólo es posible a través del diálogo interdisciplinario. Andahazi es consciente de este fenómeno, y no sólo hereda las palabras de Borges, sino también su estilo de escritura ironista, construyendo una narrativa que, como muy bien lo señala Hugo Hortiguera, se teje a partir de textos ajenos, "a través de la intercalación de fragmentos, de párrafos o expresiones que se transcriben de otros textos, a veces traducidos, a veces en su lengua original". De esta manera el discurso andahaziano se instituye como el resultado de una colección de "desechos textuales [que] aparecen como costura que une o relaciona textos que juegan con deslizamientos, omisiones y supresiones". 19 Partiendo de otros textos, tanto Borges como Andahazi buscan las aporías que ellos revelan y proponen ciertas resoluciones a esas aporías mientras que al mismo tiempo ponen en evidencia otras nuevas que, también por ser metáfora, encierran un infinito y multifacético número de interpretaciones; sin embargo, ninguna interpretación en particular, por más exhaustiva que ésta pueda ser, jamás es capaz de explicar definitivamente la metáfora, haciendo posible de esta manera el permanente diálogo entre las diferentes disciplinas del conocimiento.

\footnotetext{
${ }^{19}$ Fuente electrónica (Véase en la bibliografía).
} 


\section{BIBLIOGRAFÍA}

ACZEL, Amir D.

2000 The Mystery of the Aleph: Mathematics, the Kabbalah, and the Search for Infinity. New York: Washington Square Press.

ANDAHAZI, Federico.

2002 El secreto de los Flamencos. Buenos Aires: Planeta.

ARISTÓTELES.

1982 Metafísica de Aristóteles. Ed. trilingüe de Valentín Garía Yebra. Madrid: Gredos, $2^{\mathrm{a}}$ edc.

BORGES, Jorge Luis.

1989 Obras completas. Barcelona: Emecé, 4 vols.

1997 Textos recobrados (1919-1929). Buenos Aires: Emecé.

DAVIDSON, Donald.

2001 Inquiries into Truth and Interpretation. New York: Oxford U.P.

GUTIÉRREZ GIRARDOT, Rafael.

1959 Jorge Luis Borges: ensayo de interpretación. Madrid: Ínsula.

HERNÁNDEZ, Juan Antonio.

2000 "Biografía del infinito: La noción de transfinitud en Georg Cantor y su presencia en la prosa de Jorge Luis Borges", Signos Literarios y

HORTIGUERA, Hugo

Lingüisticos (II.2, diciembre 2000):131-139.

2002 "Entre palabras: partes privadas, silencios y cuerpos ocultos en la narrativa argentina de los '90. El caso Federico Andahazi', Ciberletras, 2002:6

KLINE, Morris.

http://www.lehman.cuny.edu/ciberletras/v06/hortiguera.html

1980 Mathematics: The Loss of Certainty. Oxford: Oxford U.P.

KURLAT ARES, Silvia G.

2005 “Sobre 'El Aleph' y 'El Zahir': La búsqueda de la escritura de Dios”, Variaciones Borges 19 (2005):5-22.

MERRELL, Floyd.

1991 Unthinking Thinking: Jorge Luis Borges, Mathematics, and the New Physics. Indiana: Purdue U.P.

PLATO.

1989 The Collected Dialogues of Plato. Ed. Edith Hamilton and Huntington Cairns. New Jersey: Princeton U.P.

REY, Pedro B.

2002 'Un bello misterio escrito con pincel', La Nación. Buenos Aires: sept. 2002

http://www.lanacion.com.ar/429113

RUSSELL, Bertrand.

1997 The Problems of Philosophy. New York: Oxford U.P. 